Journal of Energy and
Environmental Sustainability
Journal homepage : www.jees.in

\title{
Characterization and Physicochemical Properties of Biodiesel Produced from Castor Oil Using Refluxed Calcined Snail Shell
}

\author{
Muhammad Sabiu Jibrin ${ }^{a *}$, Chika Muhammad ${ }^{a}$, Mukhtar Muhammad ${ }^{\mathrm{a}}$, Aliyu Sarkin Baki ${ }^{\mathrm{b}}$, \\ Dhikrah Ibrahim ${ }^{\mathrm{b}}$
}

${ }^{a}$ Department of Pure and Applied Chemistry, Usmanu Danfodiyo University, P.M.B. 2346, Sokoto, Nigeria; ${ }^{b}$ Department of Microbiology, Usmanu Danfodiyo University, P.M.B. 2346, Sokoto, Nigeria

A R T I C L E I N F O

Received : 03 May 2018

Revised : 19 June 2018

Accepted : 05 July 2018

Keywords:

castor seed, refluxed calcined snail shell,

characterization, snail shell,

biodiesel and methyl ester.

\begin{abstract}
A B S T R A C T
In this work, biodiesel was produced from castor oil using $\mathrm{CaO}$ obtained from snail shell as a catalyst. The castor oil was extracted using soxhlet extraction method and pretreated in order to upgrade it physicochemical properties for efficient transesterification reaction. The catalyst used was prepared from snail shell using the hydrothermal method and characterized using FTIR and TGA/DTA analysis. The yield of biodiesel produced is $99.68 \%$. The methyl ester yield was analyzed using GC-MS as $99.12 \%$. The major methyl ester compositions in the biodiesel produced are $(86.18 \%) 9$ - octadecenoic acid- 12- hydroxyl-, methyl ester, [R- (Z)]-, (10.06 \%) 9- 0ctadecenoic acid [Z]-, methyl ester,(1.19\%) Hexadecanoic acid, methyl ester and $(1.17 \%)$ Methyl stearate. The physicochemical properties of biodiesel produced show that the biodiesel produced may be used in a diesel engine with little
\end{abstract} modifications or blend with conventional diesel.

\section{Introduction}

The diminution of fossils fuels and increasing demand for conventional energy worldwide have been the main apprehension of scientist nowadays (Ismail et al., 2016; Refaat et al., 2008). An incessant supply of energy is crucial to support the human activities such as industrialization, construction, transportation, and agriculture. As the conventional energy sources are finite, there is a need to generate a sustainable alternative, nonconventional energy to support the civilization (Hribernik and Kegl, 2007; Ma et al., 1999).

Biodiesel is defined by the European Parliament in Directive 2003/ $30 /$ EC (DEPC, 2003) as a "methyl-ester produced from vegetable or animal oil, of diesel quality, to be used as biofuel". Biodiesel is characterized by its biodegradability, nontoxic, renewability, ease of production and agricultural origin (Knothe et al., 2006). The $\mathrm{CO}_{2}$ emissions of biodiesel combustion can be considered as recyclable by the growing plants, emissions of SOx, CO, unburnt hydrocarbons, and particulate matter are lower than those of petroleum diesel (Coronado et al., 2009).

Transesterification of vegetable oils and animal fats is the primary way to make biodiesel (Encinar et al., 2010). Transesterification is a three-step reversible reaction of vegetable oils or animal fats with a short-chain alcohol usually methanol to form fatty acid methyl esters (FAMEs) and glycerol (Encinar et al., 2010). The presence of a catalyst is needed. Among the alcohols that can be used in the transesterification process are methanol, ethanol, propanol, butanol and amyl alcohol. Methanol is used most commonly because of its low cost and its physical and chemical advantages (polar and shortest chain alcohol). The stoichiometric ratio for transesterification requires three moles of alcohol. However, the molar ratio is associated with the type of catalyst used and higher molar ratios result in greater ester conversion in a shorter time (Ma and Hanna, 1999).

Heterogeneous base catalysts eliminate the need for the neutralization of homogeneous base catalysts with acids and the removal of water in the commercial production of biodiesel, thereby lowering its production cost (Cho and Seo, 2010). Among the heterogeneous catalysts, calcium oxide has derived researchers' attention because it is a cheap and abundantly available in nature as a limestone and also from seashells in the form of calcium carbonate, $\mathrm{CaCO}_{3}$. Calcium oxide can be reused up to 3 times in transesterification reaction which made it an economic catalyst. As the calcium oxide was derived from the natural source, it is environmentally friendly and causes no harm to the ecosystem. Thus, calcium oxide was suitable to be used in large-scale production of biodiesel for commercial purpose as it needs no post-treatment prior to its disposal to the environment (Kouzu et al., 2008).

About chemical and physical characteristics, castor oil composition is $80-90 \%$ ricinoleic acid, 3-6 \% linoleic acid, 2-4 \% oleic acid and 1-5\% saturated fatty acids (Scholz and da Silva, 2008). Ricinoleic acid is the main fatty acid from castor oil; this fatty acid possesses 18 carbons with three highly reactive functional groups: the carbonyl group in $1^{\text {st }}$ carbon, the double linking or unsaturation in $9^{\text {th }}$ carbon and the hydroxyl group in $12^{\text {th }}$ carbon. This feature causes castor oil properties are different from other vegetable oils (Conceição et al., 2007). The high content of ricinoleic acid, with a hydroxyl group, is the reason for castor oil has especially

\footnotetext{
*Corresponding Author: muhammadsabiu44@gmail.com
} 
high viscosity and density. Castor oil is also characterized by its high stability, high hygroscopicity and its solubility in alcohol, which affects the transesterification reaction (Ogunniyi, 2006).

The review of the different research achievements on vegetable oils and biodiesel as an alternative fuel for a compression ignition engine were collated as follow: Ismail et al. (2016) conducted an experiment of biodiesel production from castor oil by using calcium oxide derived from mud clam shell. The calcium oxide synthesized from mud clam shell shows good catalytic performance and physicochemical properties as a heterogeneous catalyst for biodiesel production. The optimum parameters of calcium oxide catalyzed transesterification of castor oil where determined as 1:14 oil to methanol molar ratio, $3 \% \mathrm{w} / \mathrm{w}$ catalyst concentration, $60{ }^{\circ} \mathrm{C}$ reaction temperature and 2- hours reaction time. Reusability test shows that the synthesized calcium oxide from mud clam shell is reusable up to 5 times.

Sanchez et al. (2015) studied the biodiesel production from castor oil under subcritical methanol condition using potassium methoxide catalyst. The effect of molar ratio and reaction temperature on alkyl ester formation was studied. It was concluded that by coupling the catalyst with subcritical methanol, biodiesel was synthesized from castor oil with a high yield.

Darnoko and Cheryan (2000) reported data on palm oil kinetics. It was observed that the rate of alkali-catalyzed $(\mathrm{KOH})$ transesterification in a batch reactor increased with temperature up to $60{ }^{\circ} \mathrm{C}$. The further increase in temperatures did not reduce the time to reach the maximum conversion. The free fatty acid and moisture content in the material are the key parameters for determining the viability of the vegetable oil transesterification process. Ma et al. (1999) studied the effect of free fatty acids and water content in the transesterification of beef tallow. The presence of water had more negative effects on the transesterification than free fatty acids. They concluded that for best results, the water content and the free fatty acid content in beef tallow should be kept below $0.06 \%$ $\mathrm{w} / \mathrm{w}$ and $0.5 \% \mathrm{w} / \mathrm{w}$ respectively.

The objectives of this work were to extract, refine and study physicochemical properties of castor seed oil, to prepare catalyst from snail shell using the hydrothermal method and characterize it using Thermogravimetric Analysis (TGA) and Fourier transform infrared (FTIR), and finally to produce and determine the physicochemical properties of biodiesel produced and characterize it using GC/MS.

\section{Material and Methods}

\subsection{Sampling and Preparation}

The Castor seed was procured from Yandodo, Kano State. The seed was sundried to reduce the moisture content and it was then ground to reduce the particle size in preparation for extraction. The Castor seed was de-shelled. The de-shelled seed was oven dried at $90{ }^{\circ} \mathrm{C}$ for 45 minutes. The dried seeds were grounded using motor and pestle and weighed.

\subsection{Oil Extraction Process}

Extraction of castor oil was carried out by soxhlet extraction method as reported by Edison et al. (2012). The extracted oil had undergone some pre-treatment such as degumming with water to remove the easily hydratable phospholipids and metals, addition of phosphoric to convert the remaining non- hydratable phospholipids ( $\mathrm{Ca}$ and $\mathrm{Mg}$ salts) into hydratable phospholipids and further neutralized of free fatty acids with slight excess of $\mathrm{NaOH}$ solution, followed by washing out of soaps and hydrated phospholipids (Nakarmi and Joshi, 2014).

\subsection{Preparation of Catalyst}

The Calcium oxide catalyst that was used in this study was synthesized from snail shell through hydrothermal method. The snail shell was obtained from local Danmadanho in Kano state. The snail shell was washed with $1 \%$ aqueous solution of sulfuric acid in order to remove dirt and stains on the shell surface. The shell was ground into powder size using motor and pestle. The snail shell powder was then thermally decomposed in a furnace at $800{ }^{\circ} \mathrm{C}$ for 3 hours. The calcined shell was then refluxed in distilled water at $105{ }^{\circ} \mathrm{C}$ for 6 hours. The sample was then filtered, oven dried at $120{ }^{\circ} \mathrm{C}$ for 2 hours. The refluxed calcined snail shell was recalcined at $800{ }^{\circ} \mathrm{C}$ for 2 hours using muffle furnace to produce fine calcium oxide (Ismail et al., 2016).

\subsection{Transesterification of Castor Seed Oil}

The transesterification was carried out in $500 \mathrm{~cm}^{3}$ two necks round bottom flask as reactor equipped with condenser, thermometer and hotplate magnetic stirrer. The $45 \mathrm{~g}$ of refined castor oil was initially charged into the reactor, and then preheated to $50^{\circ} \mathrm{C}$. In order to maintain the catalytic activity, the solution of $0.225 \mathrm{~g}(0.5 \mathrm{wt} \%)$ of $\mathrm{CaO}$ (refluxed calcined snail shell) in $9.169 \mathrm{~g}$ (1:6 oil to methanol ratio) methanol was freshly prepared so that prolonged contact with the air would not diminish the effectiveness of the catalyst through interaction with moisture and carbon dioxide. The solution was preheated to $50{ }^{\circ} \mathrm{C}$ in the water bath and then added to the preheated oil after which the reaction was timed at 1 hour and the agitation was kept at $300 \mathrm{rpm}$. After the reaction time, the mixture was allowed to settle under gravity for 24 hours in the separating funnel. Two distinctive layers were formed: the upper layer consisted of methyl ester, methanol traces, residual catalyst, and other impurities, whereas the lower layer consisted of glycerin, excess methanol, catalyst, and other impurities. After separation from the glycerin layer, the methyl ester layer was centrifuged and then purified by washing with hot distilled water at $60^{\circ} \mathrm{C}$ until the washing water had a $\mathrm{pH}$ value similar to that of distilled water (Nakarmi and Joshi, 2014). The hot distilled water-to-crude methyl ester ratio was 1:1. To prevent the possibility of losing the methyl ester due to emulsion formation, the washing was done gently. After then the weight of biodiesel was taken and yield was determined.

\subsection{GC-MS Analysis of Biodiesel Produced}

The oil composition and methyl ester content were assayed using a GC/MS machine in the multi-purpose laboratory in Ahmadu Bello University (ABU), Zaria.

\subsection{Physicochemical Properties}

The physicochemical properties of biodiesel produced, crude and refined castor oil were determined. The pour point, cloud point and flash point were analyzed using methods as reported by Faduka, (2001). The moisture content, $\mathrm{pH}$ value, specific gravity, refractive index, acid value, saponification value and iodine were determined through the method as reported by Akpan et al. (2006) and Kyari, (2008). The kinematic viscosity was analysed using cannon viscometer model 2020 as described in cannon manual, (2017), the API gravity and cetane index were determined by the methods ASTM D1250 and ASTM D611. The cetane number and the high heating value was determined by methods reported by Mohibbe et al., (2005), and Sivaramakrishnan and Ravikumar, (2012).

\section{Results and discussion}

The physicochemical properties of biodiesel produced, crude and refined castor oil were determined and presented in Table 1 . The acid value which is an important parameter to be considered in base-catalyzed transesterification, as high acid value resulted in high soap formation (Kyari, 2008), increasing difficulties in separation of biodiesel and hence, affect the biodiesel yield. The refined castor oil has lower acid value than crude castor oil which indicates the efficiency of pretreatment of oil for base-catalyzed transesterification.

\subsection{Catalyst Characterizations}

\subsubsection{Physical Observation}

The colour of the ground snail shell was ash colour, after calcination the colour changes to fairly white and after the catalyst was refluxed and recalcined, the colour was completely transformed to brightly white. The ground snail shell was granular but after refluxing and recalcination (thermal hydration) it becomes finely pulverized, which indicates an increase in surface area, hence, indicate improve catalytic activity and basicity of the refluxed calcined snail shell.

\subsubsection{FT - IR Analyses}

The infrared spectrum of ground snail shells (mainly $\mathrm{CaCO}_{3}$ ), calcined snail shell (mainly $\mathrm{CaO}$ ) and refluxed calcined snail shell (mainly $\mathrm{CaO}$ ) were analyzed using FT-IR machine, and collated in Table 2. A sharp peak can be seen at $1450 \mathrm{~cm}^{\prime \prime 1}$ of ground snail shell (calcium carbonate), the absorption peaks correspond to $\mathrm{C}-\mathrm{O}$ symmetrical stretching vibration of carbonates (Garcia et al., 2008). The absorption peaks at $1650 \mathrm{~cm}^{\prime \prime}$ and $2350 \mathrm{~cm}^{\prime \prime 1}$ correspond to $\mathrm{C}=\mathrm{O}$ stretching vibration of carbonates. The two weak peaks at $950 \mathrm{~cm}^{\prime \prime 1}$ and $875 \mathrm{~cm}^{\prime \prime}$ correspond to the out-ofplane bending vibration of $\mathrm{C}-\mathrm{O}$ bonds of carbonates. Upon calcination, the calcium carbonate was thermally decomposed into calcium oxide and loses carbonate. Thus, this leads to the decrease of characteristics peaks of carbonates on the IR spectrum of the synthesized calcium oxide. The reduced intensity of absorption band which corresponds to carbonates can be seen at $2200 \mathrm{~cm}^{\prime 1}, 1650 \mathrm{~cm}^{\prime 1}, 1450 \mathrm{~cm}^{\prime 1}, 920 \mathrm{~cm}^{\prime 1}$, and $800 \mathrm{~cm}^{\prime 1}$ on the IR spectrum of calcium oxide from snail shell (there is a higher reduction in the intensity of the refluxed calcined snail shell (GalvánRuiz et al., 2009). 
Table 1: Physicochemical properties of crude and refined castor oil, and biodiesel produced

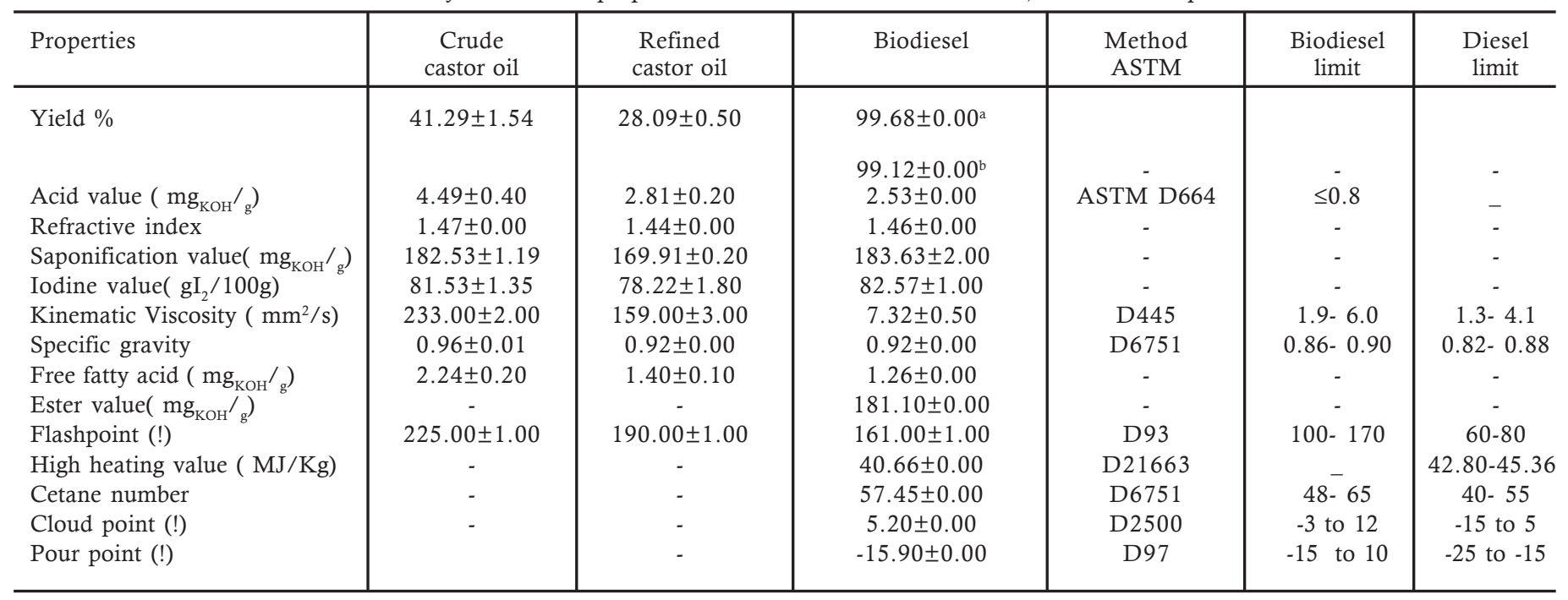

Key: $a$ is a yield obtained from raw biodiesel, $b$ is a methyl ester contents of biodiesel analyzed using GC/MS.

Values are Arithmetic Mean \pm Standard Deviation of three replicate determinations.

Table 2: FT-IR Results of ground, Calcined and Refluxed Calcined Snail Shell

\begin{tabular}{l|l|l}
\hline Nature of the Peak & Range $\mathbf{( c m - 1 )}$ & Functional Group \\
\hline Broad & $3870-3300$ & O-H stretching vibration (peak decreased upon calcination and refluxing) \\
Short peak & $3000-2900$ & C-H stretching vibration \\
intense & 1650 & C=O stretching vibration (peak intensity significantly decreased upon calcinations and refluxing) \\
medium & 1450 & C-O stretching vibration \\
short & 950 and 875 & C-O out of plane bending vibration \\
Sharp peak & 500 & Ca-O (peak sharply increased upon calcinations and refluxing) \\
\hline
\end{tabular}

A sharp peak around $500 \mathrm{~cm}^{\prime 1}$ of the infrared spectrum corresponds to functional group $\mathrm{Ca}-\mathrm{O}$ from calcium carbonates. The $\mathrm{Ca}-\mathrm{O}$ peak intensity reduced as calcium carbonate was decomposed into calcium oxide (Galván-Ruiz et al., 2009). The absorption band in the range of 3651$3870 \mathrm{~cm}^{\prime \prime}$ on the infrared spectrum corresponds to a hydroxyl group. The absorption peak of the hydroxyl group is normally ascribed to the presence of calcium hydroxide. The existence of hydroxyl group resulted from absorption of atmospheric moisture during FT-IR analysis which subsequently formed calcium hydroxide. This phenomenon was common due to the high hydrophilicity nature of the compound (Tan et al., 2015).

\subsubsection{DTA/TGA Analysis}

The TGA and DTA curves prepared of $\mathrm{CaO}$ catalyst from snail shell in Fig. 1, show that the initial weight of refluxed calcined snail shell at $14.50 \mathrm{mg}$, as the temperature rises $91.57^{\circ} \mathrm{C}$ at 4.08 minutes, the weight started to reduced to $14.30 \mathrm{mg}$ which might be due to the loss of moisture absorbed due to its high hydrophilicity (Tan et al., 2015). Since the thermogravimetric analysis was carried out in an air medium, the catalyst absorbed carbonate [1], this leads to the rapid increases in the weight of the catalyst to $14.70 \mathrm{mg}$ at 30 minutes. As the temperature rises above $471{ }^{\circ} \mathrm{C}$ at 42.62 minutes, the compound decomposes rapidly and weight reduces to $13.40 \mathrm{mg}$. However, (Fig. 1) the TGA and DTA curves of prepared $\mathrm{CaO}$ catalyst showed the significant weight loss at $856.88{ }^{\circ} \mathrm{C}$ (from 13.40 to $9.31 \mathrm{mg}$ ) at 83.29 which may be due to loss of extremely low volatile impurities and carbonates bounded to the surface of $\mathrm{CaO}$ respectively (Tan et al., 2015). Then the curve stabilized, which indicate the end of thermal decomposition.

\subsection{Physicochemical properties of biodiesel produced \\ 3.2.1 Biodiesel Yield}

The percentage yield of the biodiesel obtained is $99.68 \%$. The amount obtained is economically significant and it indicates substantial improvement toward obtaining expected theoretical yield (100\%). The high yield may be as a result of the refining of the oil and significant improvement of the activity of the prepared catalyst. The yield obtained which is high than (96.7\%) that obtained by Ismail et al. (2016) and 98\% obtained by Saribiyik et al. (2010). The comparative yield of $99.58 \%$ by Birla et al. (2012) was obtained by transesterifying waste frying oil with methanol in the presence of calcined snail shell, and similar yield of $99.50 \%$ was obtained by Chen et al. (2013).

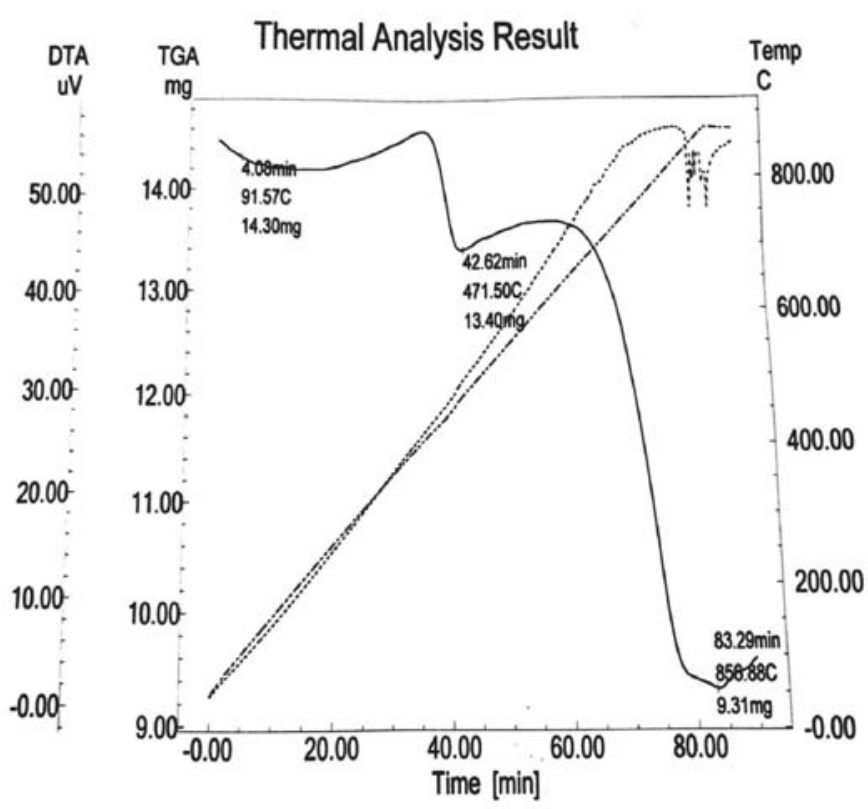

Fig. 1 : Thermogravimetric analysis of refluxed calcined snail shell 


\subsubsection{Acid Value}

The acid value of the biodiesel oil is $2.53 \pm 0.00 \mathrm{mgKOH} / \mathrm{g}$ which is greater than $(0.567 \mathrm{mgKOH} / \mathrm{g})$ obtained by Asmare and Gibbiye (2015) of castor oil biodiesel and less than $(3.8 \mathrm{mgKOH} / \mathrm{g})$ obtained by AlHarbawy and Al-Mallah (2014) for castor oil biodiesel. Also, the value is greater than the maximum value as specified by ASTM as indicated Table 1. Hence, direct use of the oil might cause corrosion in the engine fuel system and the biodiesel may decompose into different products. Hence, the oil should be neutralized prior to storage or use in the diesel engine.

\subsubsection{Saponification Value}

The saponification value of the biodiesel as presented in Table 1 is $183.63 \pm 2.00 \mathrm{mgKOH} / \mathrm{g}$ which is comparable with the result $(182.40$ $\mathrm{mgKOH} / \mathrm{g}$ ) for castor oil biodiesel obtained by Encinar et al. (2010) and (179.06 mgKOH/g) obtained by Al-Harbawy and Al-Mallah (2014). The saponification is useful for the detection of oil or fat with a high proportion of the lower fatty acid (Mohibbe et al., 2005). Ester value is a measure of the amount of saponifiable glyceride in the oil (Omahu and Omale, 2017). The ester value was determined by subtracting the acid value from the saponification value. The biodiesel has a high ester value of $181.10 \pm 00 \mathrm{mgKOH} / \mathrm{g}$ and this was justified by the GC/ MS analysis which indicates $99.1212 \%$ fatty acid methyl ester contents.

\subsubsection{Iodine Value}

The more iodine is attached, the higher is the iodine value, and the more reactive, less stable, softer, and more susceptible to oxidation and rancidification is the oil/ fat (Sokoto et al., 2011). In Table 1, the iodine value of the biodiesel produced is $82.57 \pm 1.00 \mathrm{gI}_{2} / 100 \mathrm{~g}$ which is greater than $\left(58.34 \mathrm{gI}_{2} / 100 \mathrm{~g}\right)$ obtained by Al-Harbawy and Al-Mallah (2014). And, similar result $\left(82.49 \mathrm{gI}_{2} / 100 \mathrm{~g}\right)$ was obtained by Encinar et al., (2010). The iodine value obtained shows low degree of unsaturated fatty acid methyl esters and coincided with GC/ MS results, which show major methyl esters (9- octadecenoic acid - 12- hydroxyl-, methyl ester, [R- (Z)]- (86.1838\%), 9- octadecenoic acid [Z]-, methyl ester (10.0618\%)) which are monounsaturated compounds. The iodine value is within ASTM specification for Biodiesel (Table 1).

\subsubsection{Kinematic Viscosity}

Kinematic viscosity is the most important property of oil because it affects the fluidity, lubricity and atomization of the fuel (Srinibas and Satyarthi, 2011). Whereas the viscosity of produced biodiesel as presented in Table 1 , was about $7.32 \pm 0.50 \mathrm{~mm}^{2} / \mathrm{s}$ at $40{ }^{\circ} \mathrm{C}$. The value is slightly lower than $9.8 \mathrm{~mm}^{2} / \mathrm{s}$ determined by Rengasamy et al. (2014). Exactly $95.4 \%$ reduction was achieved in kinematic viscosity by a transesterification reaction. The obtained result is not within the ASTM standard $\left(1.9-6.0 \mathrm{~mm}^{2} / \mathrm{s}\right.$,). The similar kinematic viscosity values castor oil biodiesel of 14.85 and $24.0 \mathrm{~mm}^{2} / \mathrm{s}$ were observed by Encinar et al., (2010) and Srinivas et al., (2011) respectively. The reason for the higher viscosity of the castor oil biodiesel is due to the presence of hydroxyl group in its 12th carbon molecular structure of 9- octadecenoic acid, 12hydroxyl-, methyl ester [R-(Z)]- which is the predominant ester in the oil, as reported by Deshpande et al. (2012). Therefore the direct use of the biodiesel produced may lead to poor combustion and increases exhaust emission. Hence, the produced biodiesel may be used as fuel by adding additives or by blending with petrodiesel.

\subsubsection{Specific Gravity}

The specific gravity is a key fuel property, which affects the mass of fuel injected into the combustion chamber. This property directly affects the engine performance characteristic because the fuel injection pump meter works on by volume, not by mass (Rengasamy et al., 2014). After transesterification process, the specific gravity of biodiesel as presented in Table 1 was reduced to $0.92 \pm 0.00$. The obtained value is slightly greater than the specification of biodiesel ASTM D6751 standard. A similar result was observed by Encinar et al. (2010) which found that the specific gravity of castor oil biodiesel was 0.917 using $1 \mathrm{wt} \%$ of potassium methoxide as catalyst. The specific gravity of obtained biodiesel was observed to be slightly higher than that of the conventional diesel. This result indicates that the slightly greater mass of obtained biodiesel may be delivered into the diesel engine.

\subsubsection{Flash Point}

The flash point is the minimum temperature at which fuel gives momentary flash on ignition under specified test conditions. It is an important parameter for storage, handling and safety of the fuel. The flash point of biodiesel produced at optimum yield in Table 1 is $161.00 \pm 0.00$ ${ }^{\circ} \mathrm{C}$. This value is within the standard of 100 to $170{ }^{\circ} \mathrm{C}$ as indicated in the ASTM standard. The flash point value obtained is higher than $205^{\circ} \mathrm{C}$ and $200{ }^{\circ} \mathrm{C}$ obtained by Encinar et al., (2010) and Srinivas et al., (2011) respectively. Based on the results, the produced biodiesel is considered to be safer for storage and handling purposes when compared to the conventional diesel.

\subsubsection{Cloud Point and Pour Point}

The cloud point is the temperature at which dissolved solids are no longer completely soluble, precipitating as a second phase giving the fluid a cloudy appearance (Rengasamy et al., 2014). While the pour point is carried out to determines the freezing point of the sample. In Table 1, the cloud and pour point of the biodiesel are 5.2 and $-15.90{ }^{\circ} \mathrm{C}$ and a similar result was obtained by Rengasamy et al. (2014) $\left(6^{\circ} \mathrm{C}\right)$. Sumathi et al. (2008) which observed that the cloud point for castor oil biodiesel produced using acid/base catalyst was $3^{\circ} \mathrm{C}$. All the values of pour point and cloud point of the biodiesel obtained are within ASTM standard as presented in Table 1. The result of the study suggests that the obtained biodiesel may be used as fuel at low temperatures as it met the ASTM standard of pour and cloud point.

\subsubsection{Refractive Index}

This is the measure of the extent to which radiation is refracted on passing through the interface between two media. It indicates the clarity of the oil. The refractive index of the biodiesel obtained is $1.47 \pm 0.00$. A similar result was obtained by Nakarmi and Joshi, (2014), and (1.467) was obtained by Al-Harbawy and Al-Mallah (2014). The value of the refractive index produced of the biodiesel show that the oil contained minimal or no particulate matter.

\subsubsection{Cetane Number}

Generally, the higher the cetane number, the shorter the ignition delay and the higher the propensity of the fuel to ignite (Mukhtar, et al., 2015). A fuel of higher cetane number gives lower delay period and provides smoother engine operation. Biodiesel has a higher $\mathrm{CN}$ than petro-diesel because of its higher oxygen content (Sivaramakrishnan and Ravikumar, 2012). The cetane number of the biodiesel calculated in Table 1 is $57.45 \pm 0.00$, similar result (57.11) was obtained by Asmare and Gibbiye (2014). The result obtained is high than (50) of castor oil biodiesel obtained by Ingle and Nandedkar (2016) and lower than 80 obtained by Saribiyik et al. (2010). The value calculated is within the ASTM standard range $48-65$ and its appreciable good.

\subsubsection{High Heating Value of Biodiesel Produced}

One important parameter of biodiesel fuel is the higher heating value which represents the amount of heat transferred to the chamber during combustion and indicates the maximum amount of energy available in a fuel (Demirbas, 2008). It determines the suitability of the material as an alternative to diesel fuel. The High heating value calculated is $40.66 \mathrm{MJ} /$ $\mathrm{Kg}$ as presented in Table 1, which indicate the biodiesel produced contained appreciably high amount of energy. Similar results $40.5 \mathrm{MJ} /$ $\mathrm{Kg}$ of castor biodiesel was determined by Asmare and Gibbiye (2014).

\subsubsection{GC-MS Analysis of Biodiesel Produced}

The percentage compositions of fatty acids methyl esters in the biodiesel produced at optimum yield were determined using GC/MS The relative abundance of the methyl esters, show the presence of hexadecanoic acid methyl ester (1.19\%), 9- octadecenoic acid (Z) - methyl ester $(10.06 \%)$, methyl stearate $(1.18 \%)$, 9-Octadecenoic acid-12-hydroxy, methyl ester, [R-(Z)]- (86.18\%), and oxacyclotetradecane -2,11-dione, methyl ester (0.5089), this resulted to $99.1212 \%$ total methyl ester produced. And the other compounds detected which are not methyl ester are L-Arabinitol (0.7797\%) and 13-Hexyloxacyclotridec-10-en-2-one $(0.0991 \%)$.

\section{Conclusions}

The studies of biodiesel production from $R$. communis (castor seed) oil using refluxed calcined snail shell $(\mathrm{CaO})$ revealed: The pretreatments improved the physicochemical properties and efficiency of castor oil used in biodiesel production. The prepared catalyst through thermal hydration method shows significant improvement in its catalytic activity by producing significant amount $(99.68 \%)$ of biodiesel yield. The physicochemical properties of the biodiesel produced show that the oil may be used in a diesel engine with little modification or maybe use as an additive to conventional diesel. 


\section{Acknowledgements}

One of the authors, Muhammad Sabiu Jibrin (PTDF/ED/LSS/MSC/ MSJ/389/17) acknowledged Petroleum Technology Development Fund (PTDF) for sponsoring this research work.

\section{References}

Al-Harbawy, A. W. and Al-Mallah, M. K. (2014). Production and Characterization of Biodiesel from Seed Oil of Castor (Ricinus Communis L.) Plant. International Journal of Science and Technology, 3(9):508-513. ISSN: 2049-7318.

Akpan, U. G., Jimoh, A. and Mohammed, A. D. (2006). Extraction, Characterization and Modification of Castor Seed Oil. Leonardo Journal of Sciences, 8: 43-52.

Asmare, M. and Gibbiye, N. (2014). Synthesis and Characterization of Biodiesel from Castor Bean as Alternative Fuel for Diesel Engine. American Journal of Energy Engineering, 2(1): 1-15.

Birla, A., Singh, B., Upadhyay, S. N. and Sharma, Y. C. (2012). Kinetics Studies of Synthesis of Biodiesel from Waste Frying Oil Using a Heterogeneous Catalyst Derived from Snail Shell, Bioresources Technology, 106(2012): 95-100.

Chen, K. T., Wang, J. X., Dai, Y. M., Wang, P. H., Liou, C. Y., Nien, C. W., Wu J. S. and Chen, C.C. (2013). Rice Husk Ash as a Catalyst Precursor for Biodiesel Production, Journal Taiwan Institute of Chemical Engineering, 44(4): 622-629.

Cho, Y. B. and Seo, G. (2010). High Activity of Acid-treated Quail Eggshell Catalysts in the Transesterification of Palm Oil with Methanol. Bioresource Technology, 101(22): 8515-8519.

Conceição, M. M., Candeia, R. A., Silva, F. C., Bezerra, A. F. Fernandes, J. V. J. and Souza, A. G. (2007). Thermoanalytical Characterization of Castor Oil Biodiesel. Renewable and Sustainable Energy Reviews, 11: 964-975.

Coronado, C. R., Carvalho, J. A. and Silveira, J. L. (2009). Biodiesel $\mathrm{CO}_{2}$ Emissions: A Comparison with the Main Fuels in the Brazilian Market. Fuel Process Technology, 90:204-211.

Darnoko, D. and Cheryan, M. (2000). Kinetics of Palm Oil Transesterification in a Batch Reactor. Journal of the American Oil Chemists' Society, 77(12): 1263-1267.

Demirbas, A. (2008). Biofuels Sources, Biofuel Policy, Biofuel Economy and Global Biofuel Projections. Energy conversion and management, 49(8): 2106-2116.

Deshpande, D. P., Haral, S. S., Gandhi, S. S. and Ganvir, V. N. (2012). Transesterification of Castor oil. Journal of Engineering Sciences, (1): 2-7.

Edison M., John K., Philiswa M. and Mohamed B. (2012). Optimization of Process Parameters for Castor Oil Production. Proceedings of the World Congress on Engineering, 3. WCE, July 4 - 6, 2012, London, UK, ISBN: 978-988-19252-2-0, ISSN: 2078-0958 (Print); ISSN: 2078-0966 (online).

Encinar, J.M., Gonzalez, J.F., Martinez, G., Sanchez, N. and Gonzalez, C.G. (2010). Synthesis and Characterization of Biodiesel Obtained from Castor Oil Transesterification. International Conference on Renewable Energy and Power Quality (ICREPQ 11), 1(9): 1078- 1083.

Fuduka, H., Kando, A. and Noda, H., (2001).Biodiesel Fuel Production by Transesterification of Oils. Journal of Bioscience and Bioengineering, (92): 405415.

Galván-Ruiz, M., Hernández, J., Baños, L., Noriega-Montes, J., Mario, E. and Rodríguez, G. (2009). Characterization of Calcium Carbonate, Calcium Oxide, and Calcium Hydroxide as Starting Point to the Improvement of Lime for their Use in Construction. Journal of Materials in Civil Engineering, 21(11): 694-698,

García, J., López, T., Alvarez, M., Aguilar, D. H. and Quintana, P. (2008). Spectroscopic, Structural and Textural Properties of $\mathrm{CaO}$ and $\mathrm{CaO}-\mathrm{SiO} 2$ Materials Synthesized by Sol-gel with Different Acid catalysts, Journal of Non-Crystalline Solids, 354(29): 729-732.

Hribernik, A. and Kegl, B. (2007). The Influence of Biodiesel on the Combustion and Emission Characteristics of a Diesel Engine. Strojniški vestnik - Journal of Mechanical Engineering, 53(10): 683-695.

Ingle, S. S. and Nandedkar, V. M. (2016). Castor Oil Biodiesel an Alternative Fuel for Diesel in Compression Ignition. IOSR Journal of Mechanical and Civil Engineering, ISSN(e): 2278- 1684, ISSN(p): 2320- 334X: 10-13.

Ismail, S., Ahmad, A. S., Anr, R. and Hamdan, S. (2016). Biodiesel Production from Castor
Oil by Using Calcium Oxide Derived from Mud Clam Shell. Journal of Renewable Energy, 2016: 5274917, http://dx.doi.org/10.1155/2016/5274917, 12/03/ 2017 at $02: 45 \mathrm{pm}$.

Knothe, G., Sharp C. A. and Ryan, T. W. (2006). Exhaust Emissions of Biodiesel, Petrodiesel, Neat Methyl Esters, and Alkanes in a New Technology Engine. Energy and Fuels, 20: 403-408.

Kouzu, M., Kasuno, T., Tajika, M., Sugimoto, Y., Yamanaka, S. and Hidaka, J. (2008).Calcium Oxide as a Solid Base Catalyst for Transesterification of Soybean Oil and its Application to Biodiesel Production. Fuel, 87(12): 2798-2806.

Kyari, M. Z. (2008). Extraction and Characterization of Seed Oils. International Agrophysics, 22: 139-142.

Ma, F. and Hanna, M. A. ( 1999). Biodiesel Production: A Review. Bioresource Technology, 70: 1-15,

Ma, F., Clements, L. D., and Hanna, M. A. (1999). The Effect of Mixing on Transesterification of Beef Tallow. Bioresource Technology, 69(3), 289-293.

Ma, F., Clements, L. D., and Hanna, M. A. (1999). The Effect of Mixing on Transesterification of Beef Tallow. Bioresource Technology, 69(3), 289-293.

Mohibbe, A., Amtul, W. and Nahar, N. M. (2005). Prospect and Potential of Fatty Acid Methyl Esters of Some Non- traditional Seeds Oils for Use as Biodiesel in India. Biomass Bioenergy, 2(9): 293- 302.

Mukhtar, M., Muhammad, C., Dabai, M.U., and Mamuda, M.(2015). Ethanolysis of Calabash (LageneriaSinceraria) Seed Oil for the Production of Biodiesel. American Journal of Energy Engineering, 2(6): 141 -145.

Nakarmi, A. and Joshi, S. (2014). A study on Castor Oil and its Conversion into Biodiesel by Transesterification Method. Nepal Journal of Science and Technology, 15(1): 45-52.

Ogunniyi, D. S. (2006). Castor oil: A vital industrial raw material. Bioresource Technology, 97:1086-1091.

Omahu, O. J. and Omale, A. C. (2017). Physicochemical Properties and Fatty Acid Composition of castor Bean Ricinus Communis L. Seed Oil. American Journal of Applied and Industrial Chemistry, 3(1): 1-4. doi: 10.11648/j.ajaic.20170301.11.

Refaat, A. A., Attia, N. K., Sibak, H. A., El Sheltawy, S. T. and El Diwani, G. I. (2008). Production Optimization and Quality Assessment of Biodiesel from Waste Vegetable Oil. Environmental Science and Technology 5: 75-82.

Rengasamy, M., Mohanraj, S., Vardhan, S. H., Balaji, R. and Pugalenthi V. (2014) Transesterification of Castor Oil Using Nano-sized Iron Catalyst for the Production of Biodiesel. Journal of Chemical and Pharmaceutical Science, JCHPS Special Issue 2, ISSN: 0974- 2115.

Sánchez, N., Encinar, J. M., Martinez, G. and González, J. F. (2015). Biodiesel Production from Castor Oil under Subcritical Method Conditions. International Journal of Environmental Science and Development. 6(1): 562 doi: 10.7763/IJESD.2015.

Saribiyik, O. Y., Nzcanli, M., Serin, H., Serin, S. and Aydin, K. (2010). Biodiesel Production from Ricinus Communis Oil and its Blends with Soybean Biodiesel. StronjniŠki Vestnik- Journal of Mechanical Engineering, 56(12): 811-816.

Scholz, V. and da Silva, J. N. (2008). Prospects and Risks of the Use of Castor Oil as a Fuel. Biomass and Bioenergy, 32: 95-100.

Sivaramakrishnan, K. and Ravikumar, P. (2012). Determination of Cetane Number of Biodiesel and Its Influence on Physical Properties. ARPN Journal of Engineering and Applied Sciences, 2(2): ISSN 1819- 6608.

Sokoto, M. A., Hassan, L. G., Dangoggo, S. M., Ahmad, H. G. and Uba A. (2011). Influence of Fatty Acid Methyl Esters on Fuel Properties of Biodiesel Produced from the Seed Oil of Cucurbita Pepo. Nigerian Journal of Basic and Applied Science, 19(1): 81-86, ISSN 0794-5698.

Srinivas, D., and Satyarthi, J. K. (2011). Biodiesel Production from Vegetable Oils and Animal Fat Over Solid Acid Double-Metal Cyanide Catalysts. Catalysis Surveys from Asia, 15(3): 145-160.

Sumathi, S., Chai, S. P., and Mohamed, A. R. (2008). Utilization of Oil Palm as a Source of Renewable Energy in Malaysia. Renewable and Sustainable Energy Reviews, 12(9):2404-2421.

Tan, Y. H., Abdullah, M. O., Nolasco-Hipolito, C. and Taufiq-Yap, Y. H. (2015). Waste Ostrich- and Chicken-egg Shells as Heterogeneous Base Catalyst for Biodiesel Production from Used Cooking Oil, Catalyst Characterization and Biodiesel Yield Performance. Applied Energy, 160: 58-70. 